\title{
Uncertainty Analysis on Risk Assessment of Water Inrush in Karst Tunnels
}

\author{
Yiqing Hao, ${ }^{1,2}$ Xiaoli Rong, ${ }^{1}$ Linjian Ma, ${ }^{1,3}$ Pengxian Fan, ${ }^{1}$ and Hao Lu' ${ }^{1}$ \\ ${ }^{1}$ State Key Laboratory of Disaster Prevention \& Mitigation of Explosion \& Impact, College of National Defense Engineering, \\ PLA University of Science and Technology, Nanjing 210007, China \\ ${ }^{2}$ High-Tech Institute, Fan Gong-ting South Street on the 12th, Qing Zhou, Shan Dong, China \\ ${ }^{3}$ State Key Laboratory for Geomechanics and Deep Underground Engineering, China University of Mining and Technology, \\ Xuzhou 221116, China
}

Correspondence should be addressed to Linjian Ma; patton.4400@163.com

Received 26 June 2016; Accepted 27 October 2016

Academic Editor: David González

Copyright (C) 2016 Yiqing Hao et al. This is an open access article distributed under the Creative Commons Attribution License, which permits unrestricted use, distribution, and reproduction in any medium, provided the original work is properly cited.

\begin{abstract}
An improved attribute recognition method is reviewed and discussed to evaluate the risk of water inrush in karst tunnels. Due to the complex geology and hydrogeology, the methodology discusses the uncertainties related to the evaluation index and attribute measure. The uncertainties can be described by probability distributions. The values of evaluation index and attribute measure were employed through random numbers generated by Monte Carlo simulations and an attribute measure belt was chosen instead of the linearity attribute measure function. Considering the uncertainties of evaluation index and attribute measure, the probability distributions of four risk grades are calculated using random numbers generated by Monte Carlo simulation. According to the probability distribution, the risk level can be analyzed under different confidence coefficients. The method improvement is more accurate and feasible compared with the results derived from the attribute recognition model. Finally, the improved attribute recognition method was applied and verified in Longmenshan tunnel in China.
\end{abstract}

\section{Introduction}

Risk management became an integral part of most underground projects during the late 1990s [1]. Water inrush is one of the major problems in underground construction projects, especially in karst regions. It severely endangers the safety of underground tunnel constructions and operations in China, resulting in tremendous casualties and economic loss. Water inrush in karst tunnel has to satisfy three necessary conditions of water source, karst conduit, and potential energy.

Water inrush can be described exactly by the potential energies of water leaking from karst conduit. Based on the mechanism of water inrush in karst tunnel, it can be categorized into geological flaws and no geological flaws [2]. The research of water inrush mainly focuses on three aspects: factor indexes, assessment with no geological flaws, and assessment with geological flaws.

There exist many perspectives on risk, and traditionally some of the perspectives have been seen as representing completely different frameworks, making the exchange of ideas and results difficult [3]. Risk assessment of water inrush with no geological flaws established the model by the theory of rock mass mechanics. Yao et al. [4] built numerical models for the roof fracture and seepage development rule using RFPA $2 \mathrm{D}$ and COMSOL to analyze the changes in fracture zone, stress, water pressure, and seepage vector with the advancement of working face, respectively.

Risk assessment of water inrush with geological flaws normally use neural network method, AHP, FAHP, GIS, fuzzy mathematical method, attribute mathematical method, and so on $[5,6]$. Risk analysis provides a procedure, which should take into account the uncertainties [7-9]. Some scholars have solved the uncertainties in water inrush with the probability method. Jurado et al. developed a general probabilistic risk assessment (PRA) framework to quantify risks driven by groundwater to the safety of underground constructions [10]. Sousa and Einstein estimated the risk during tunnel construction using Bayesian Network [11]. X. P. Li and Y. N. 
Li [12] studied a forecasting system for water inrush based on GIS. Further, a case study on the diversion tunnel groups of Jinping II Hydropower Station based on GIS is provided by X. P. Li and Y. N. Li [13]. Wang et al. constructed a secondary fuzzy comprehensive evaluation system to evaluate the risk of floor water invasion [14]. Meng et al. put forward a coal floor water inrush risk assessment method based on a conventional water inrush coefficient, considering the lithology and structure features [15]. Li et al. developed a spatiotemporal dynamic model through an analysis of the factors influencing temporal changes of water inrush spreading in roadways [16]. Li et al. developed the methodology which consists of two attribute recognition models: one is for design stage, and the other is for construction stage [17].

In the risk assessment of water inrush in karst tunnels, the biggest problem is that the classification is different and the result is not rational. However, it can be effectively solved by the risk assessment model based on attribute comprehensive evaluation system, according to the principle of maximum membership degree law. Many literatures present a series of researches on the integrated attribute evaluation system model.

When using the model based on attribute synthetic evaluation system, the value of evaluation index and attribute measure influence the assessment results directly. Based on ordered partition class and attribute recognition criterion, the attribute synthetic evaluation system can effectively identify and perform comparative analysis. Also, the attribute synthetic evaluation system effectively overcomes some shortcomings of other identification methods such as fuzzy recognition theory and can effectively reduce the loss of information in a calculation. Therefore, the synthetic evaluation system attribute has been successfully applied to the risk predication, risk evaluation, and risk decision of water inrush in karst tunnel. Previous methods usually adopt a definite value. Nevertheless, the geology in karst regions is uncertain, and it has the stochastic character. Also, the attribute is uncertain too. So, there are two basic problems before the viewpoints on the stochastic rock engineering to analyze the risk assessment of water inrush.

(1) The uncertainty of geology induces the uncertainty of evaluation index value. The evaluation indices generally rely on objective factors such as hydrogeology and geology factors. The values of evaluation index are always different from each other even in the same condition. Therefore, the value of evaluation index must account for the randomness.

(2) Uncertainty of attribute measure: in the model based on attribute synthetic evaluation system, the attribute level of evaluation index is quantitatively depicted as a constant by the attribute measure. It is more reasonable using an interval compared to a constant to depict the attribute measure, ascribed to the uncertainty of attribute measure.

In this paper the statistical characteristic about the value of evaluation index and attribute measure is taken into account with respect to the uncertainty of risk assessment in water inrush. An improved attribute recognition approach is proposed to calculate probabilities of risk level utilizing attribute synthetic evaluation system and Monte Carlo sampling distribution. The results would be more scientific and reasonable compared to other methods.

\section{Probabilities of the Evaluation Indices Based on Geology}

Indices and criteria for risk assessment of water inrush are based on the statistical information about geology in karst tunnels, and several influencing factors of water inrush are selected as the attribute evaluation indices. Formation lithology is normalized, and strata inclination is divided into Level III and Level IV in the range of $\left[0^{\circ}, 10^{\circ}\right]$. The specific indices and criteria are shown in Table 1 [17].

There are many uncertain factors in the evaluation of the rock engineering [18]. The statistical characteristics of physical and mechanical parameters of rock mass are described as normal distribution, Poisson distribution, and Gumbel extreme distribution [19]. Discontinuity of rock mass (e.g., strata inclination and rock mass fissure) is described as normal distribution [20-22]. The factors related to human are described as normal distribution.

The probability distribution of strata inclination, for instance, is calculated. Suppose the actual measurement indices are $x_{1}, x_{2}, \ldots, x_{n}$, and the mean value and standard deviation can be calculated. The strata inclination is the biggest included angle between the rock stratum and the imaginary horizontal plane, which is called the true dip angle. The strata inclination is measured along the true direction of rock by a compass. A set of strata inclinations of the rock stratum was measured near the Longmen mountain tunnel, and the data are given as follows (unit: ${ }^{\circ}$ ): 78, 78, 78, 78.5, 79.5, $79.5,80,80.5,80.5,80.5,81,81.5,81.5,81.5,81.9,82,82,82,82$, $82,82,82,82,82.9,83,83,83,83,83.2,83.3,83.5,83.5,83.5$, $83.5,83.5,84,84,84,84,84,84.5,84.5,84.5,83.7,83.7,83.7$, $84.7,84.7,84.9,84.9,84.9,85,85,85,85,85,85.5,85.5,85.5$, $85.8,85.9,85.9,86,86,86,86,86.5,86.5,86.5,86.5,87,87,87$, $87,87,87.5,88,88,88,88.5,88.7,88.8,88.8,89,89,89,89.2,89.5$, $89.5,89.5,89.5,89.5,90,90$, and 90 . The mean value and the standard deviation are 84.74 and 3.16, respectively. By using $\chi^{2}$ text, fitting of normal distribution is done. The distribution map is shown in Figure 1.

The parameters of probabilistic distribution function for indices include mean value and standard deviation which can be calculated using measurement data. If the data is a value interval, the mean value can be calculated using the value interval and the standard deviation can be calculated using $3 \sigma$ principle.

\section{Probabilities of the Attribute Measure}

3.1. Attribute Measure. Attribute measure is the characterization that represents the level of a certain attribute of the element. As " $x \in C$ " means " $x$ has the attribute of $C$," this expression only gives a brief qualitative description. For this reason, a number to depict the level of " $x$ has the attribute of $C$ " is needed. Then, the number is denoted as $\mu_{x}(C)$, which is called the attribute measure of " $x \in C$ "; the linear function of attribute measure was previously used in model based on attribute synthetic evaluation system to avoid the mutation 
TABLE 1: Indices and criteria for risk assessment of water inrush in karst tunnels.

\begin{tabular}{|c|c|c|c|c|}
\hline \multirow{2}{*}{ Indices for risk assessment of water inrush } & \multicolumn{4}{|c|}{ Risk grade } \\
\hline & IV & III & II & I \\
\hline Formation lithology $I_{1}$ & $0 \sim 4.2$ & $4.2 \sim 10.4$ & $10.4 \sim 25.4$ & $>25.4$ \\
\hline Unfavorable geological conditions $I_{2}$ & $<60$ & $60 \sim 70$ & $70 \sim 85$ & $85 \sim 100$ \\
\hline Groundwater level $I_{3}$ & $<10$ & $10 \sim 30$ & $30 \sim 60$ & $>60$ \\
\hline Landform and physiognomy (proportion of negative landform area) $I_{4}$ & $<20$ & $20 \sim 40$ & $40 \sim 60$ & $>60$ \\
\hline Modified strata inclination $I_{5}$ & $0 \sim 5$ & $5 \sim 10$ & $10 \sim 25$ & $25 \sim 45$ \\
\hline Contact zones of dissolvable and insoluble rock $I_{6}$ & $<60$ & $60 \sim 70$ & $70 \sim 85$ & $85 \sim 100$ \\
\hline Layer and interlayer fissures $I_{7}$ & $<60$ & $60 \sim 70$ & $70 \sim 85$ & $85 \sim 100$ \\
\hline
\end{tabular}

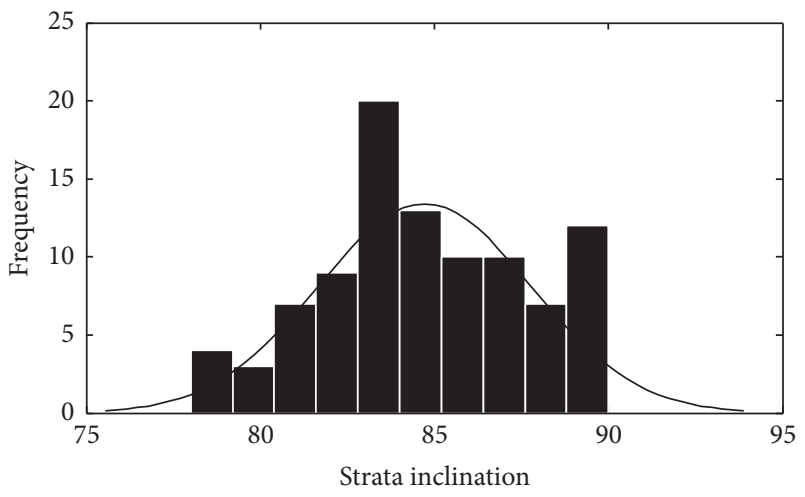

FIgURE 1: Histogram and distribution of strata inclination.

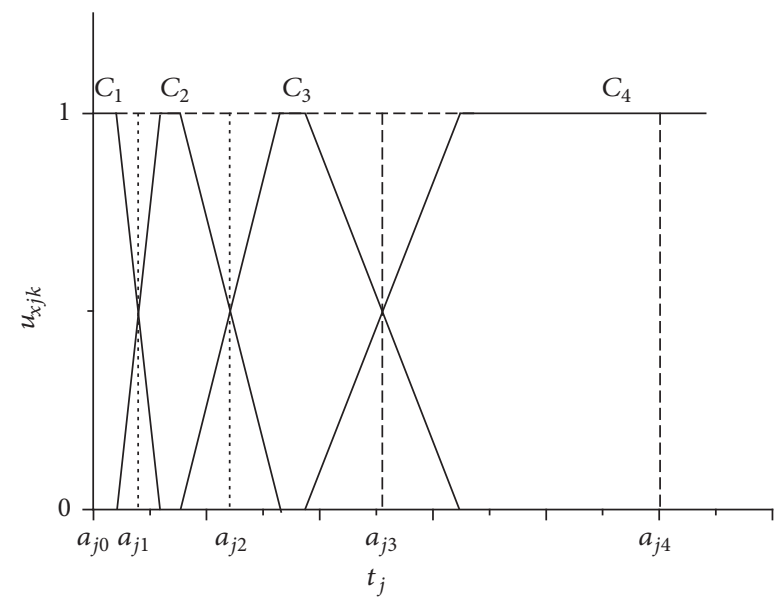

FIGURE 2: Linearity attribute measure curve.

which was generated from the change of risk, as shown in Figure 2.

There is often no linear relationship between the influencing factors and the risk of water inrush in karst tunnel. So, when the attribute recognition model is applied to comprehensive risk evaluation of water inrush, the evaluation results of attribute recognition model based on linear measure function often have relatively large errors. Thus, the reliability

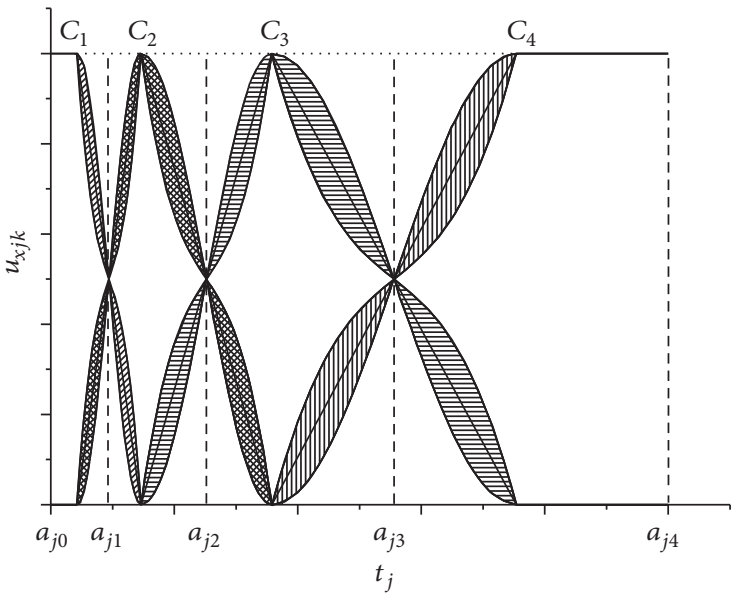

FIGURE 3: Trigonal attribute measure curve.

of the evaluation results is reduced. However, it is better to depict the attribute measure by a limited value interval rather than a certain value. This means that the attribute measure perturbs in the value interval. The disturbing region is called attribute measure belt. In the attribute measure belt, the attribute measure value of the element on the starting point or terminal point is 0 or 1 , while the value of the element on the middle is 0.5 . Therefore, if the value of the element is 0 or 1 , it is the clearest point; if the value is 0.5 , it is the fuzziest point. That is to say, it is on the middle point between 0 and 1 . When the value of a point is certain, its value of attribute measure is 0 or 1, the attribute measure belt will be tentatively determined, as shown in Figure 3.

3.2. Attribute Measure Belt. Suppose $x$ is one element of $X, C$ is an attribute set, and $\left\{C_{1}, C_{2}, C_{3}, C_{4}\right\}$ is one partition of $C$. Based on the partition of attribute set, the domain element is determined that its attribute measure value is 0,1 , or 0.5 , as shown in Table 2.

The attribute measure function is not arbitrary, but it must follow three principles [23]. The distributional characteristics of the function relate to actual background. The distributional function has three forms: concave function, convex function, and linearity function. If attribute measure 
TABLE 2: Domain elements of attribute measure.

\begin{tabular}{lccc}
\hline Grade & \multicolumn{3}{c}{ Attribute measure } \\
& 0 & 1 & 0.5 \\
\hline$C_{1}$ & $\left(a_{j 1}+a_{j 2}\right) / 2$ & $\left(a_{j 0}+a_{j 1}\right) / 2$ & $a_{j 1}$ \\
$C_{2}$ & $\left(a_{j 0}+a_{j 1}\right) / 2,\left(a_{j 2}+a_{j 3}\right) / 2$ & $\left(a_{j 1}+a_{j 2}\right) / 2$ & $a_{j 1}, a_{j 2}$ \\
$C_{3}$ & $\left(a_{j 1}+a_{j 2}\right) / 2,\left(a_{j 3}+a_{j 4}\right) / 2$ & $\left(a_{j 2}+a_{j 3}\right) / 2$ & $a_{j 2}, a_{j 3}$ \\
$C_{4}$ & $\left(a_{j 2}+a_{j 3}\right) / 2$ & $\left(a_{j 3}+a_{j 4}\right) / 2$ & $a_{j 3}$ \\
\hline
\end{tabular}

has a linear relationship uniformly with the domain element change, attribute measure belt with linear function is selected and used, within the range of the domain element point at which the attribute measure value is 1 . If the attribute measure value of the element varies greatly as the domain element changes, attribute measure belt with concave function is adopted. On the contrary, if the attribute measure value of the element varies slowly, attribute measure belt with convex function is adopted. The attribute measure belt is obtained based on the three forms of the distributional function and the disturbing interval of attribute measure. Based on the linear function of attribute measure, the attribute measure belt is generated (Figure 3 ). For instance, $C_{1}$, the interval of the corresponding attribute measure value changing from 1 to 0.5 is $\left[\left(a_{j 0}+a_{j 1}\right) / 2, a_{j 1}\right]$. The upper limit function of the attribute measure belt is a triangle convex function (see (1)). The lower limit function of the attribute measure belt is a triangle concave function (see (2)). The disturbing interval is symmetrical for the linear attribute measure function. Therefore the linear attribute measure function value is the mean between the upper limit function value and lower limit function value (see (3)). The rest of the attribute measure belts are established in the same way. In the disturbing interval $\left[\overline{\mu_{x j 1}}, \mu_{x j 1}\right]$, the distributional function is unclear, whereas normal distribution is ideal candidate. Its accurate distribution can be gained through big date analytics based on lots of experimental data.

$$
\begin{aligned}
\overline{\mu_{x j 1}}= & \cos ^{2}\left(\frac{2 x-a_{j 1}-a_{j 0}}{a_{j 2}-a_{j 0}} * \frac{\pi}{2}\right), \\
\underline{\underline{\mu_{x j 1}}=} & 2 * \frac{a_{j 1}+a_{j 2}-x}{a_{j 2}-a_{j 0}} \\
& -\cos ^{2}\left(\frac{2 x-a_{j 1}-a_{j 0}}{a_{j 2}-a_{j 0}} * \frac{\pi}{2}\right), \\
\mu_{x j 1}= & \frac{a_{j 1}+a_{j 2}-x}{a_{j 2}-a_{j 0}} .
\end{aligned}
$$

\section{Attribute Recognition Model Based on Uncertainty}

4.1. Random Vector of Index for Water Inrush in Karst Tunnels. The value of risk index for water inrush in karst tunnels is achieved through statistical probability distribution based on the method in Section 3. According to the probability distribution, multiple index vectors $\mathbf{T}_{\mathbf{j}}$ with $n$ dimensions are generated, as listed or summarized in Table 3.

4.2. Single Index Attribute Measure. The random number $t_{j k}$ of index vectors should have a corresponding disturbing interval on the attribute measure belt. The upper limit of the disturbing interval is obtained by the upper limit function of the attribute measure belt and the lower limit of the disturbing interval is obtained by the lower limit function of the attribute measure belt. In the disturbing interval, attribute measure value of $t_{j k}$ is a random number on the basis of normal distribution. The mean value of the normal distribution is the midpoint of disturbing interval and the standard deviation of the normal distribution can be calculated using $3 \sigma$ principle. Then, a four-dimensional stochastic vector can be generated by each component of an index vector. Components of the four-dimensional stochastic vector have a corresponding attribute measure of risk gradation. In such a manner, every index vector has a corresponding stochastic single index attribute measure matrix $U_{j}$, which can be expressed in the following form:

$$
U_{j}=\left[\begin{array}{llll}
\mu_{1 j 1} & \mu_{2 j 1} & \cdots & \mu_{n j 1} \\
\mu_{1 j 2} & \mu_{2 j 2} & \cdots & \mu_{n j 2} \\
\mu_{1 j 3} & \mu_{2 j 3} & \cdots & \mu_{n j 3} \\
\mu_{1 j 4} & \mu_{2 j 4} & \cdots & \mu_{n j 4}
\end{array}\right],
$$

where $j=(1,2, \ldots, 7)$ is number of the indexes and $n=$ $(1,2, \ldots)$ is the frequency of Monte Carlo simulations.

4.3. Multiple Indices Synthetic Attribute Measure and Probability Distribution of Risk Gradation. Multiple indices synthetic attribute measure vector $C$ can be expressed as follows [17]:

$$
\begin{aligned}
C & =\left[\begin{array}{llll}
\mu_{11} & \mu_{21} & \cdots & \mu_{n 1} \\
\mu_{12} & \mu_{22} & \cdots & \mu_{n 2} \\
\mu_{13} & \mu_{23} & \cdots & \mu_{n 3} \\
\mu_{14} & \mu_{24} & \cdots & \mu_{n 4}
\end{array}\right], \\
\mu_{x k} & =\sum_{j=1}^{7} \omega_{j} \mu_{x j k},
\end{aligned}
$$

where $x$ is $x_{\text {th }}$ time of Monte Carlo simulations; $n$ is the frequency of Monte Carlo simulations; $k$ is the risk gradation; and $\omega_{j}=(0.167,0.350,0.176,0.097,0.049,0.113,0.048)$ is comprehensive weight vector.

Distribution maps can be expressed by using programming software MATLAB. Then the risk level can be further assessed through agglomeration and overlap degree of the distribution maps.

\section{Comparison with the Attribute Recognition Model}

The risk assessment model of water inrush in karst tunnels based on attribute synthetic evaluation system is applied 
TABLE 3: Value of $I_{j}$.

\begin{tabular}{lcc}
\hline & Index values $t_{j}$ & Index vectors $\mathbf{T}_{\mathbf{j}}$ \\
\hline Formation lithology $I_{1}$ & $t_{1}$ & $\mathbf{T}_{\mathbf{1}}$ \\
Unfavorable geological conditions $I_{2}$ & $t_{2}$ & $\mathbf{T}_{\mathbf{2}}$ \\
Groundwater level $(\mathrm{m}) I_{3}$ & $t_{3}$ & $\mathbf{T}_{\mathbf{3}}$ \\
Landform and physiognomy (proportion of negative landform area) $I_{4}$ & $t_{4}$ & $\mathbf{T}_{\mathbf{4}}$ \\
Modified strata inclination $\left(^{\circ}\right) I_{5}$ & $t_{5}$ & $\mathbf{T}_{\mathbf{5}}$ \\
Contact zones of dissolvable and insoluble rock $I_{6}$ & $t_{6}$ & $\mathbf{T}_{\mathbf{6}}$ \\
Layer and interlayer fissures $I_{7}$ & $t_{7}$ & $\mathbf{T}_{7}$ \\
\hline
\end{tabular}

in Jigongling tunnel at construction contract section K19+ 509 to $\mathrm{K} 19+539$ [17]. In that paper, the risk grade of water inrush in design stage at construction contract section $\mathrm{K} 19+509$ to $\mathrm{K} 19+539$ is initially assumed to be Level I. However, the risk grade is Level II based on the practical situation. In construction stage, the index unfavorable geological conditions are classified under three types: waterbearing structure, catchments area of karst water system, and width of fault fracture zone. Then, multiple indices synthetic attribute measures are computed based on the new indices and the risk grade is modified into Level II which is identical with the practical situation. The index was regarded as a certain value in that paper, but actually the index has uncertainty characteristic. Therefore, while the index unfavorable geological conditions change, the result changes from Level I to Level II.

Based on the values about the geological and hydrogeological conditions in Jigongling tunnel at construction contract section $\mathrm{K} 19+509$ to $\mathrm{K} 19+539$, the evaluation process can be performed considering uncertainty about the index and attribute measure as follows.

(1) For the time being, normal distribution can be used to deal with the uncertainty problem. Based on the values of indices [17], the mean and standard deviation of index $I_{j}$ are shown in Table 4.

(2) According to parameters in Table 4, each index precedes one hundred thousand Monte Carlo simulations. Then 100000 groups of seven-dimensional stochastic vector are generated by using $\mathbf{T} \sim \mathbf{N}\left(t_{j}, \sigma\right)$, which include the seven indices. The vectors replace the certain values.

(3) Single index attribute measure matrix: single index attribute measure of each stochastic vector is computed by using the method in Section 3. Then one hundred thousand groups of single index attribute measures compose an attribute measure matrix $U_{j}$ (see (4)).

(4) Multiple indices synthetic attribute measures matrix is calculated with (6). Finally, the results of these simulations can be statistically analyzed to construct the histogram of synthetic attribute measures of risk grade (see Figure 4).

Based on the histogram, synthetic attribute measures of risk grade analysis are depicted as follows.

(1) The probability of risk follows a sequence of Level III < Level I < Level IV < Level II. It is noticed that the risk of level II is most likely to occur compared to other risk levels.
(2) The probabilities of risk Level III and Level I overlap with each other from 0.1 to 0.15 . The probability of risk Level II is approximately three times larger or higher than that of risk Level I and 4 times compared to that of risk Level III. Hence, considering the single probability of synthetic attribute measure, the risk level is probably Level II.

(3) Based on the synthetic attribute measures in Figure 5, the risk grade in each region is identified by using the method for the confidence coefficient [17], which influences the risk evaluation results of water inrush. Figure 5 exhibits the normalized histogram of the probabilities of water risk level computed with Monte Carlo simulations. There is a peculiar relationship between confidence coefficient and probability of risk level. Due to the uncertainty characteristic in risk assessment of water inrush, the risk evaluation results of water inrush are presented under different confidence coefficients $\lambda$ in Table 5. In general, $\lambda$ is found to be in the range of 0.6-0.7 [23]. So, the risk level may be Level III, Level II, or Level I. Among the three levels, Level II and Level I are more likely.

There are three reasons why the risk evaluation results of water inrush is Level I in design stage and modified into Level II in construction stage [17]: (1) the certain index values are chosen instead of the random numbers, which is calculated considering uncertainty of the index values; (2) the attribute measure belt is adopted instead of the linearity attribute measure; and (3) confidence coefficient influences the risk evaluation. The confidence coefficient values are different between design stage and construction stage. From Table 6, we know that if the confidence coefficient $\lambda$ is taken as 0.7 , the risk evaluation result of water inrush is Level I; if the confidence coefficient $\lambda$ is taken as 0.65 , the risk evaluation result of water inrush changes into Level II. As a result, the risk evaluation results considering uncertainty agree well with the actual construction situation.

\section{Engineering Application}

The Chengdu-Lanzhou railway is located in Chengdu and Lanzhou in China, the bridges and tunnels ratio of which reaches up to $86.05 \%$. The project crosses through three fracture zones: the Longmenshan fracture zone, Minjiang fracture zone, and Qinling fracture zone. Therefore, the construction project has a great risk of geological disaster. 
TABLE 4: Parameters of probabilistic distribution for index $I_{j}$.

\begin{tabular}{lccc}
\hline & & Mean $t_{j}$ & Standard deviation $\sigma$ \\
\hline Formation lithology & $t_{1}$ & 75 & 1.5 \\
Unfavorable geological conditions & $t_{2}$ & 60 & 1.5 \\
Groundwater level (m) & $t_{3}$ & $>75$ & 1.5 \\
Landform and physiognomy (proportion of negative landform area) & $t_{4}$ & 40 & 1.5 \\
Modified strata inclination $\left(^{\circ}\right.$ ) & $t_{5}$ & 16 & 1.5 \\
Contact zones of dissolvable and insoluble rock & $t_{6}$ & 70 & 1.5 \\
Layer and interlayer fissures & $t_{7}$ & 65 & 1.5 \\
\hline
\end{tabular}

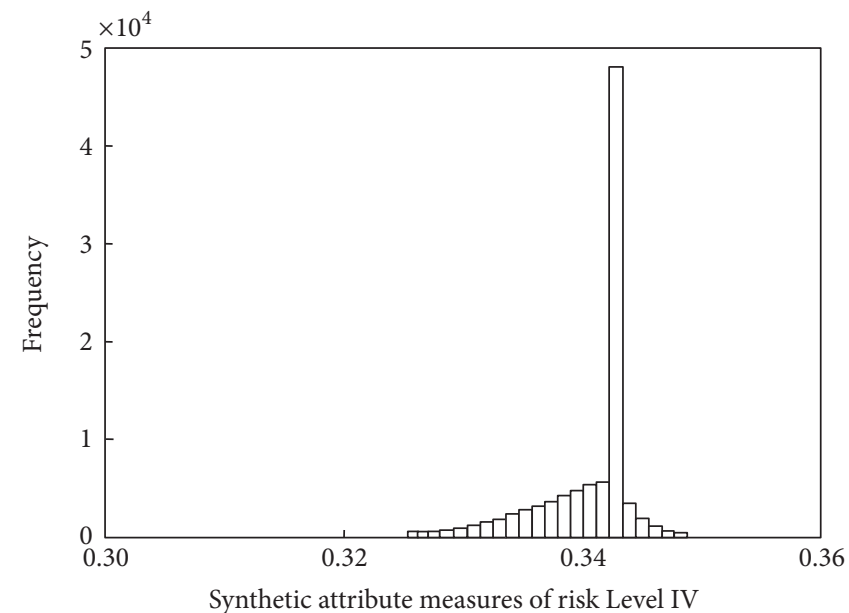

(a)

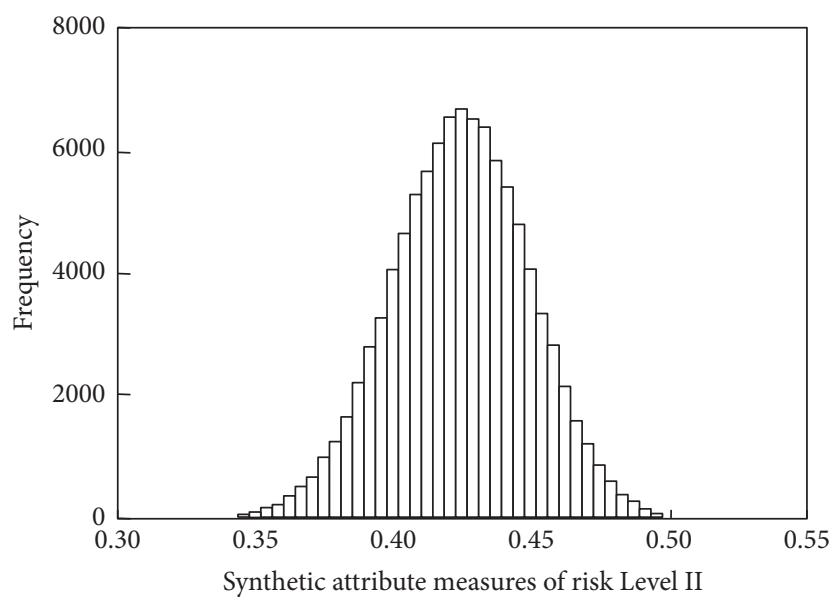

(c)

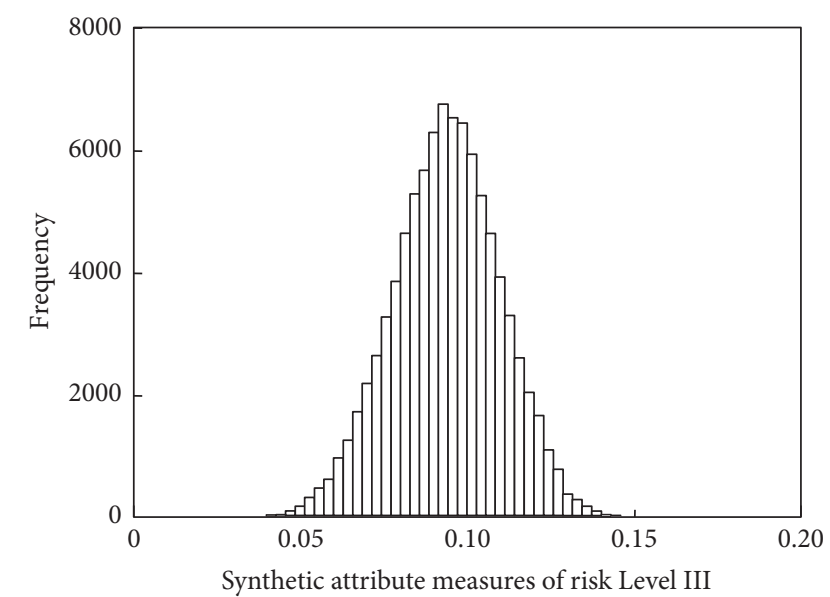

(b)

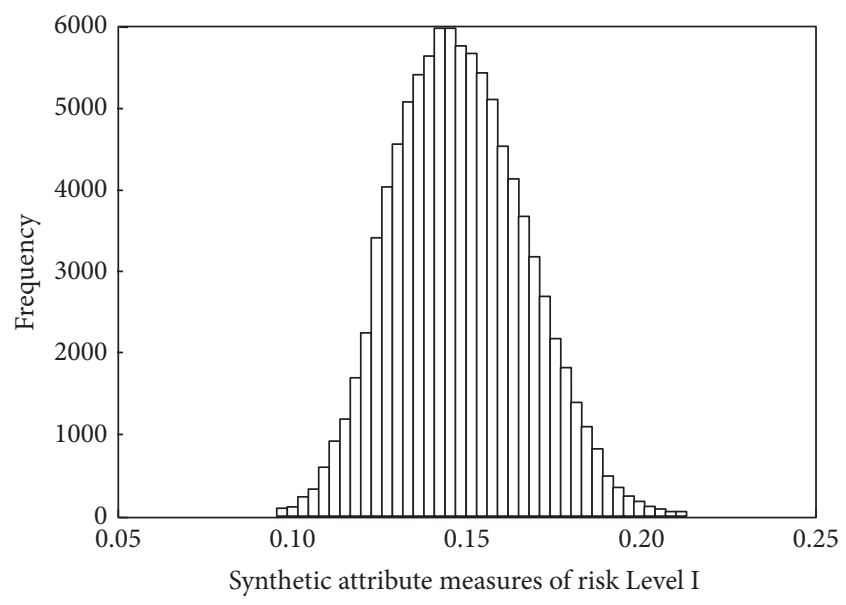

(d)

FIGURE 4: Histogram of the synthetic attribute measures of risk grade.

6.1. Engineering Background. Longmenshan tunnel is located in the Longmenshan fracture zone in the Chengdu-Lanzhou railway. It is approximately $20 \mathrm{~km}$ long, with the maximum buried depth of $1445 \mathrm{~m}$. The tunnel traverses the Peijiang river systems and the central fault belt of Longmenshan Mountain. The geological structure is relatively complex, and the topographical map is described as Figure 6. The survey section is covered by the Quaternary new landslide accumulation layer, avalanche accumulation layer, and other accumulation layers. The primal geologic formation about Longmenshan tunnel is shale, phyllite, dolomite rock, and limestone at test sections of XJ3K1 + 525 to XJ3K1 + 325 . 


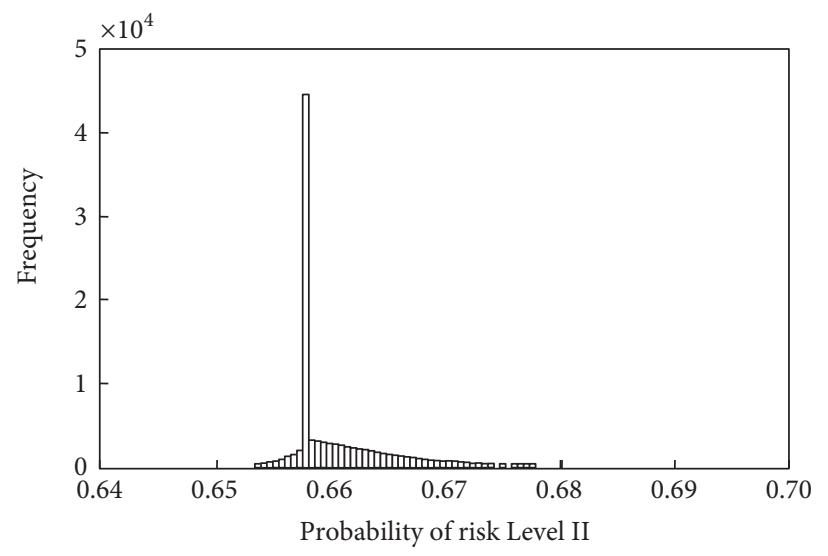

(a)

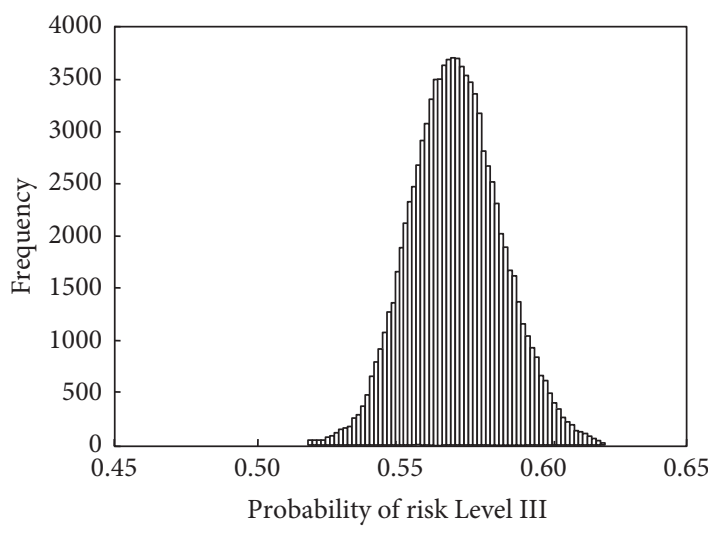

(b)

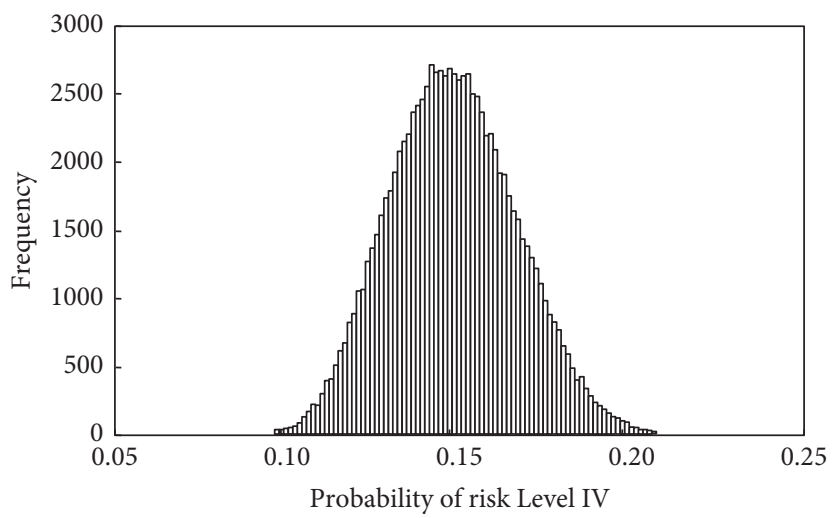

(c)

FIGURE 5: Histograms of probability of risk level.

TABLE 5: Risk evaluation risk level under different confidence coefficients.

\begin{tabular}{lc}
\hline Risk level & Confidence coefficient $\lambda$ \\
\hline $\begin{array}{l}\text { Risk Level I } \\
\text { Risk Level I or risk Level II; slanting } \\
\text { risk Level I }\end{array}$ & $(0.70,1.0)$ \\
$\begin{array}{l}\text { Risk Level I or risk Level II; slanting } \\
\text { risk Level II }\end{array}$ & $(0.658,0.7)$ \\
$\begin{array}{l}\text { Risk Level II } \\
\text { Risk Level III or risk Level II; slanting } \\
\text { risk Level II }\end{array}$ & $(0.64,0.65)$ \\
$\begin{array}{l}\text { Risk Level III or risk Level II; slanting } \\
\text { risk Level III }\end{array}$ & $(0.568,0.64)$ \\
$\begin{array}{l}\text { Risk Level III } \\
\text { Risk Level IV or risk Level III; slanting } \\
\text { risk Level III }\end{array}$ & $(0.5,0.568)$ \\
$\begin{array}{l}\text { Risk Level IV or risk Level III; slanting } \\
\text { risk Level IV }\end{array}$ & $(0.22,0.5)$ \\
Risk Level IV & $(0.15,0.22)$ \\
\hline
\end{tabular}

6.2. Risk Evaluation of Water Inrush. Based on the geology and hydrogeology of test sections, risk of water inrush is assessed. The test section is divided into five regions and risk

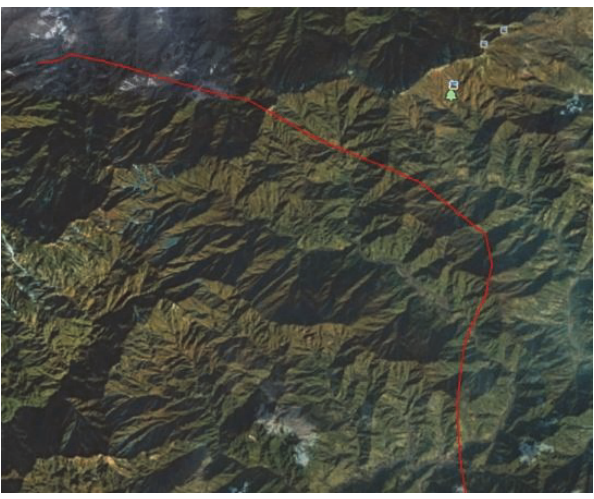

FIgURE 6: Topographical map of the tunnel.

of water inrush is evaluated in each region. The probability distributions of value indices in each region are presented in Table 6. Then, the established model is applied and the process can be performed according to the method proposed in Figure 6.

Through the calculation of the model considering uncertainties, the histograms of the probabilities of water risk level in each region are shown in Figure 6. 
TABle 6: Probabilistic distribution of value indices.

\begin{tabular}{|c|c|c|c|c|c|c|c|c|}
\hline & Indices & $I_{1}$ & $I_{2}$ & $I_{3}$ & $I_{4}$ & $I_{5}$ & $I_{6}$ & $I_{7}$ \\
\hline \multirow{2}{*}{ XJ3K1 + 525-XJ3K1 + 485} & Mean & 60 & 55 & 120 & 30 & 16 & 65 & 60 \\
\hline & Standard deviation & 0.83 & 0.83 & 1.5 & 0.83 & 0.83 & 1.5 & 1.5 \\
\hline \multirow{2}{*}{$\mathrm{XJ} 3 \mathrm{~K} 1+485-\mathrm{XJ} 3 \mathrm{~K} 1+445$} & Mean & 70 & 65 & 120 & 30 & 20 & 70 & 65 \\
\hline & Standard deviation & 0.83 & 0.83 & 1.5 & 0.83 & 0.83 & 1.5 & 1.5 \\
\hline \multirow{2}{*}{$\mathrm{XJ} 3 \mathrm{~K} 1+445-\mathrm{XJ} 3 \mathrm{~K} 1+405$} & Mean & 75 & 85 & 120 & 30 & 40 & 75 & 80 \\
\hline & Standard deviation & 0.83 & 0.83 & 1.5 & 0.83 & 0.83 & 1.5 & 1.5 \\
\hline \multirow{2}{*}{$\mathrm{XJ} 3 \mathrm{~K} 1+405-\mathrm{XJ} 3 \mathrm{~K} 1+365$} & Mean & 78 & 80 & 120 & 30 & 40 & 70 & 75 \\
\hline & Standard deviation & 0.83 & 0.83 & 1.5 & 0.83 & 0.83 & 1.5 & 1.5 \\
\hline \multirow{2}{*}{$\mathrm{XJ} 3 \mathrm{~K} 1+365-\mathrm{XJ} 3 \mathrm{~K} 1+325$} & Mean & 65 & 70 & 120 & 30 & 30 & 65 & 60 \\
\hline & Standard deviation & 0.83 & 0.83 & 1.5 & 0.83 & 0.83 & 1.5 & 1.5 \\
\hline
\end{tabular}

TABle 7: Possible risk level in each region.

\begin{tabular}{llcc}
\hline & Risk level & Confidence coefficient $\lambda$ & Risk evaluation results \\
\hline XJ3K1 + 525-XJ3K1 + 485 & Level III & $(0.6,0.7)$ & Level III \\
XJ3K1 + 485-XJ3K1 + 445 & Risk Level III or risk Level II; slanting risk Level & $(0.6,0.7)$ & level III \\
& III & $(0.6,0.7)$ & Risk level I \\
XJ3K1 + 445-XJ3K1 + 405 & Risk Level I or risk Level II; slanting risk Level I & $(0.6,0.7)$ & Risk level II \\
XJ3K1 + 405-XJ3K1 + 365 & Risk Level I or risk Level II; slanting risk Level II & $(0.6,0.7)$ & Risk level II \\
XJ3K1 + 365-XJ3K1 + 325 & Risk Level III or risk Level II; slanting risk Level II & & \\
\hline
\end{tabular}

Considering the confidence coefficient taken as 0.60.7 , the possible risk levels with different confidence coefficients are shown in Table 7 corresponding to the histograms described in Figure 7.

According to the possible risk levels and confidence coefficient, the risk evaluation results of water inrush are listed in Table 7.

6.3. Practical Situation. The excavation of number 3 inclined shaft in Longmenshan tunnel was constructed at sections $\mathrm{XJ} 3 \mathrm{~K} 1+485$. During the advanced drilling of borehole at $\mathrm{XJ} 3 \mathrm{~K} 1+439$, water seepage suddenly flowed (see Figure 8(a)). From Table 7, the risk level would be changed from Level III to Level I at section XJ3K1 +445 . So, water flowed while drilling borehole at section $\mathrm{XJ} 3 \mathrm{~K} 1+439$. Then, the borehole was pushed 6 meters ahead at section XJ3K1 + 433 and water flow increased with a definite pressure. After pulling the drill pipe, the outlet for water inrush was expanded and the water inrush increased (see Figure $8(\mathrm{~b})$ ). Water inrush of the working face kept increasing, and the whole working face was flooded finally (see Figure $8(\mathrm{c})$ ). The result of the excavation corresponds with risk evaluation.

\section{Conclusions}

The uncertainty analysis on the risk assessment attribute model of water inrush in karst tunnels was performed in this paper. Based on the uncertainties of evaluation index and attribute measure, an attribute recognition method improvement is developed and more information can be provided for decision-makers.

The probabilities of risk grade indicate that the risk evaluation results are also influenced by the confidence coefficients. While the confidence coefficient selects different value, the risk evaluation result may be different.

By comparing with attribute recognition model, this paper successfully explained the reason that the risk evaluation is different between design stage and construction stage. Basically, there are two influencing factors: (1) uncertainties of values of evaluation index and attribute measure and (2) different confidence coefficients.

The method presented was then applied in Longmenshan tunnel at section of XJ3K1 + 085-XJ3K1 + 485. Based on the new method, the risk evaluation results of water inrush show that the risk level of water inrush is very high, and sure enough water inrush occurs at section XJ3K1 +445 . So, the results used in this method to predict the risk level of water inrush in the construction of Longmenshan tunnel are in accord with the actual situation and have high reliability.

The method about uncertainties can also be utilized in other recognition models. The probability distributions of evaluation index values and attribute measures will be more objective and reasonable through big data analysis. In 


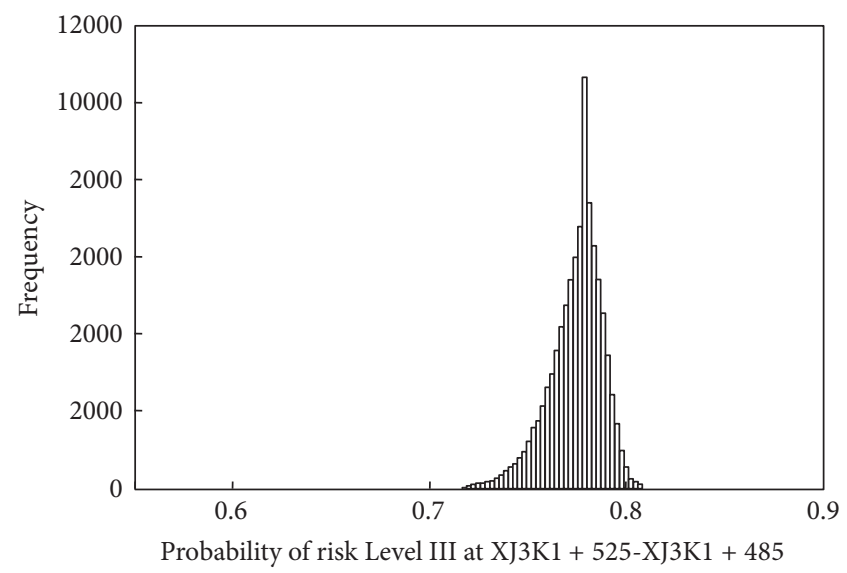

(a)

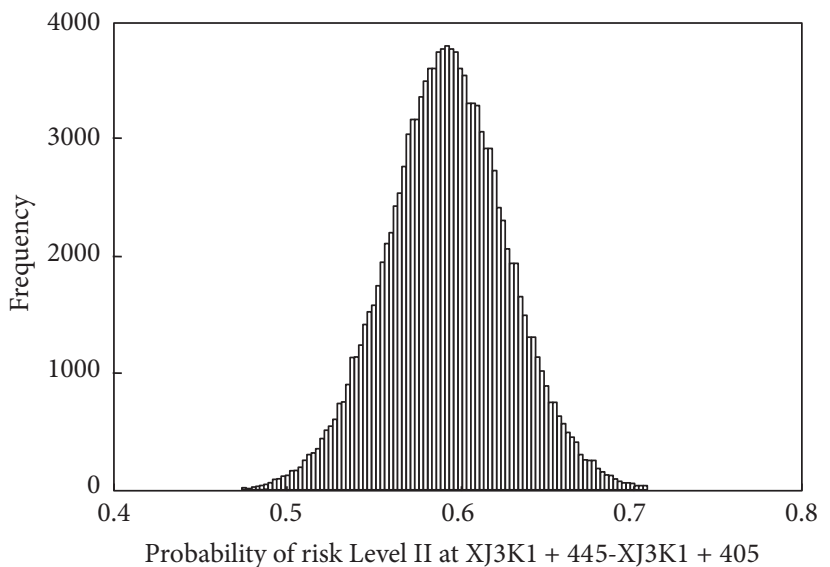

(c)

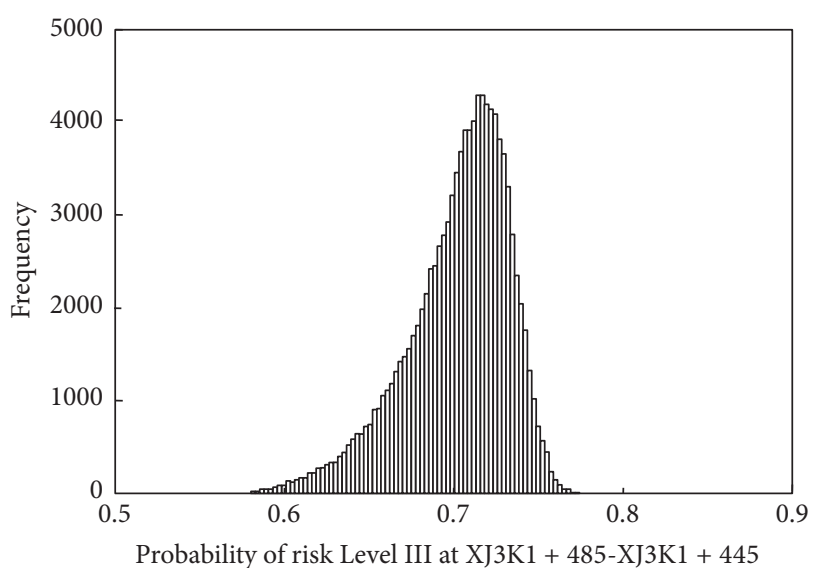

(b)

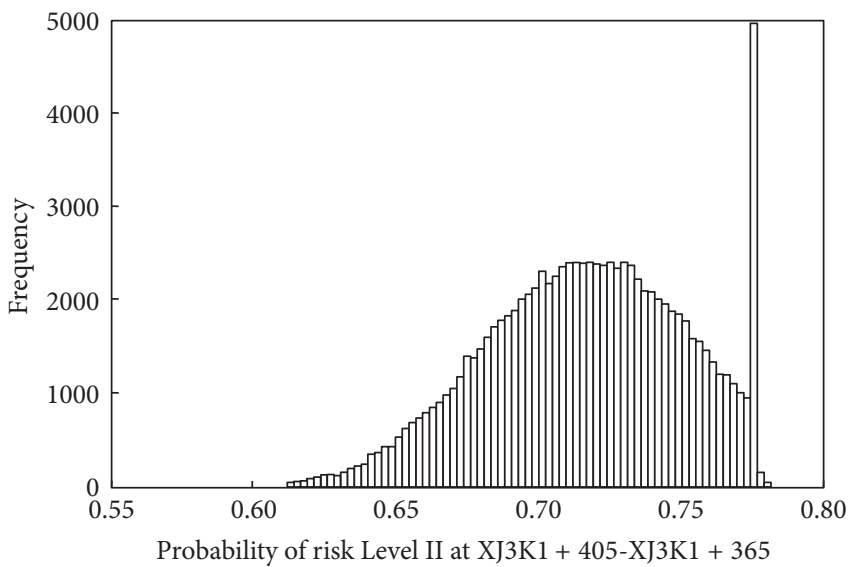

(d)

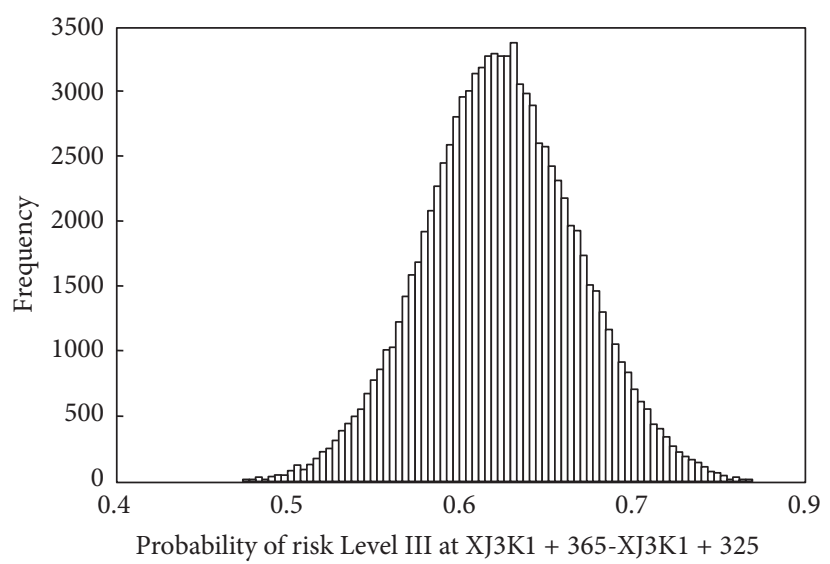

(e)

FIGURE 7: Histograms of probability of risk level in each region.

addition, it is very important to gain the confidence coefficient objectively.

\section{Competing Interests}

The authors declare that they have no competing interests.

\section{Acknowledgments}

The authors would like to acknowledge the financial support from the National Basic Research Program of China (973 Program, no. 2013CB036005), the National Natural Science Foundation of China (nos. 51527810, 51309234, 51308543, 


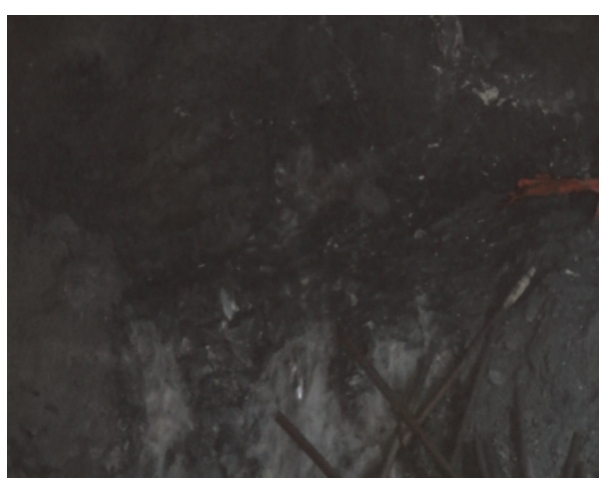

(a) Water seepage at $\mathrm{XJ} 3 \mathrm{~K} 1+439$

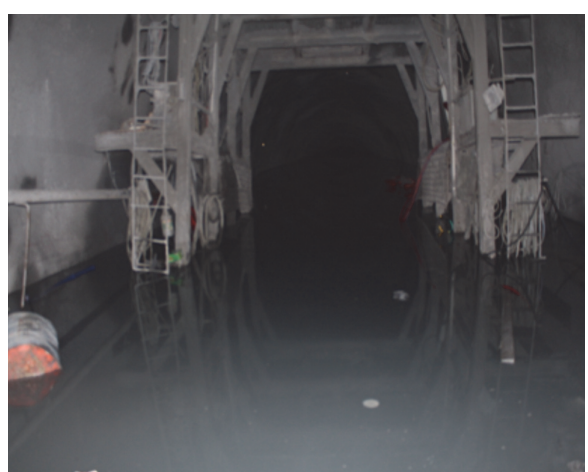

(b) Water flow at $\mathrm{XJ} 3 \mathrm{~K} 1+439$

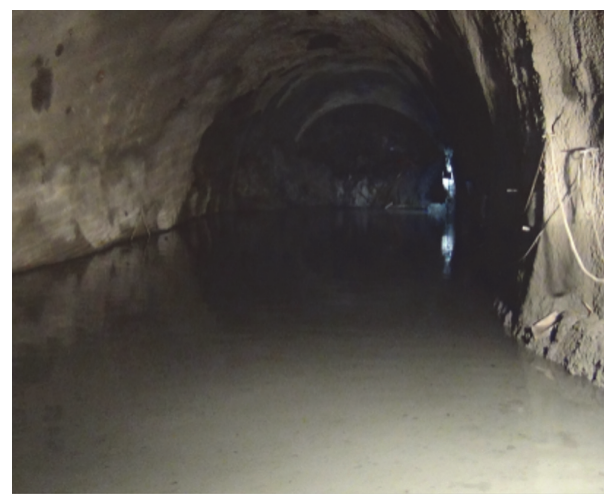

(c) Water inrush at $\mathrm{XJ} 3 \mathrm{~K} 1+439$

FIGURE 8: Water inrush of practical situation.

51309233, 51304219, and 51409258), and the Natural Science Foundation of Jiangsu Province (BK20130065). The authors also acknowledge the financial support from the Open Foundation of State Key Laboratory for Geomechanics and Deep Underground Engineering (SKLGDUEK1403) and the China Postdoctoral Science Foundation (2015M570451).

\section{References}

[1] S. D. Eskesen, P. Tengborg, J. Kampmann, and T. H. Veicherts, "Guidelines for tunnelling risk management: international Tunnelling Association, Working Group 2," Tunnelling and Underground Space Technology, vol. 19, no. 3, pp. 217-237, 2004.

[2] L. P. Li, Study on catastrophe evolution mechanism of karst water inrush [Ph.D. thesis], Shandong University, Jinan, China, 2009 (Chinese).

[3] T. Aven, "Perspectives on risk in a decision-making contextreview and discussion," Safety Science, vol. 47, no. 6, pp. 798806, 2009.

[4] B. H. Yao, H. Bai, and B. Y. Zhang, "Numerical simulation on the risk of roof water inrush in Wuyang Coal Mine," International Journal of Mining Science and Technology, vol. 22, no. 2, pp. 273277, 2012.

[5] K.-C. Hyun, S. Min, H. Choi, J. Park, and I.-M. Lee, "Risk analysis using fault-tree analysis (FTA) and analytic hierarchy process (AHP) applicable to shield TBM tunnels," Tunnelling and Underground Space Technology, vol. 49, pp. 121-129, 2015.
[6] S. Mandal and J. Maiti, "Risk analysis using FMEA: fuzzy similarity value and possibility theory based approach," Expert Systems with Applications, vol. 41, no. 7, pp. 3527-3537, 2014.

[7] H. H. Einstein, "Risk and risk analysis in rock engineering," Tunnelling and Underground Space Technology, vol. 11, no. 2, pp. 141-155, 1996.

[8] M. L. Koç, "Risk assessment of a vertical breakwater using possibility and evidence theories," Ocean Engineering, vol. 36, no. 14, pp. 1060-1066, 2009.

[9] M. Khalaj, A. Makui, and R. Tavakkoli-Moghaddam, "Riskbased reliability assessment under epistemic uncertainty," Journal of Loss Prevention in the Process Industries, vol. 25, no. 3, pp. 571-581, 2012.

[10] A. Jurado, F. De Gaspari, V. Vilarrasa et al., "Probabilistic analysis of groundwater-related risks at subsurface excavation sites," Engineering Geology, vol. 125, pp. 35-44, 2012.

[11] R. L. Sousa and H. H. Einstein, "Risk analysis during tunnel construction using Bayesian Networks: Porto Metro case study," Tunnelling and Underground Space Technology, vol. 27, no. 1, pp. 86-100, 2012.

[12] X. P. Li and Y. N. Li, "Study and application of forecasting system for water inrush under high pressure in Xiamen Submarine Tunnel Construction based on GIS," Procedia Environmental Science, vol. 10, pp. 999-1005, 2011.

[13] X. P. Li and Y. N. Li, "Research on risk assessment system for water inrush in the karst tunnel construction based on GIS: case study on the diversion tunnel groups of the Jinping II Hydropower Station," Tunnelling and Underground Space Technology, vol. 40, pp. 182-191, 2014. 
[14] Y. Wang, W. F. Yang, M. Li, and X. Liu, "Risk assessment of floor water inrush in coal mines based on secondary fuzzy comprehensive evaluation," International Journal of Rock Mechanics \& Mining Sciences, vol. 52, pp. 50-55, 2012.

[15] Z. P. Meng, G. Q. Li, and X. T. Xie, "A geological assessment method of floor water inrush risk and its application," Engineering Geology, vol. 143-144, pp. 51-60, 2012.

[16] C. P. Li, J. J. Li, Z. X. Li, and D. Y. Hou, "Establishment of spatiotemporal dynamic model for water inrush spreading processes in underground mining operations," Safety Science, vol. 55, pp. 45-52, 2013.

[17] S.-C. Li, Z.-Q. Zhou, L.-P. Li, Z.-H. Xu, Q.-Q. Zhang, and S.-S. Shi, "Risk assessment of water inrush in karst tunnels based on attribute synthetic evaluation system," Tunnelling and Underground Space Technology, vol. 38, pp. 50-58, 2013.

[18] H. Wang and Z. W. Zhuang, "Determination of membership function in fuzzy reliability analysis," Electronic Product Reliability and Environmental Testing, vol. 32, no. 2, pp. 189-286, 2002 (Chinese).

[19] J. P. Xu, H. T. Hu, and A. S. Zhang, "On statistical characteristics of physical and mechanical parameters in slope rock mass," Chinese Journal of Rock Mechanics and Engineering, vol. 18, no. 4, pp. 382-386, 1999.

[20] J. A. Hudson and S. D. Priest, "Discontinuity frequency in rock masses," International Journal of Rock Mechanics and Mining Sciences \& Geomechanics Abstracts, vol. 20, no. 2, pp. 73-89, 1983.

[21] R. F. Wallis and M. S. King, "Discontinuity spacings in a crystalline rock," International Journal of Rock Mechanics and Mining Sciences \& Geomechanics Abstracts, vol. 17, no. 1, pp. 6366, 1980.

[22] Z. Sen and A. Kazi, "Discontinuity spacing and RQD estimates from finite length scanlines," International Journal of Rock Mechanics and Mining Sciences \& Geomechanics Abstracts, vol. 21, no. 4, pp. 203-212, 1984.

[23] Q. S. Cheng, "Attribute mathematics-attribute measure and attribute statisties," Mathematics in Practice and Theory, vol. 28, no. 2, pp. 97-107, 1998 (Chinese). 


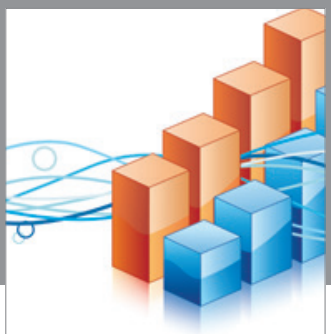

Advances in

Operations Research

vatem alat4

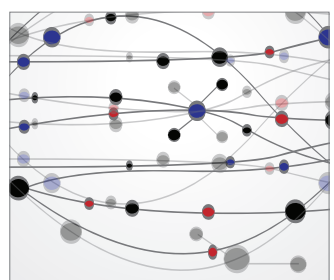

\section{The Scientific} World Journal
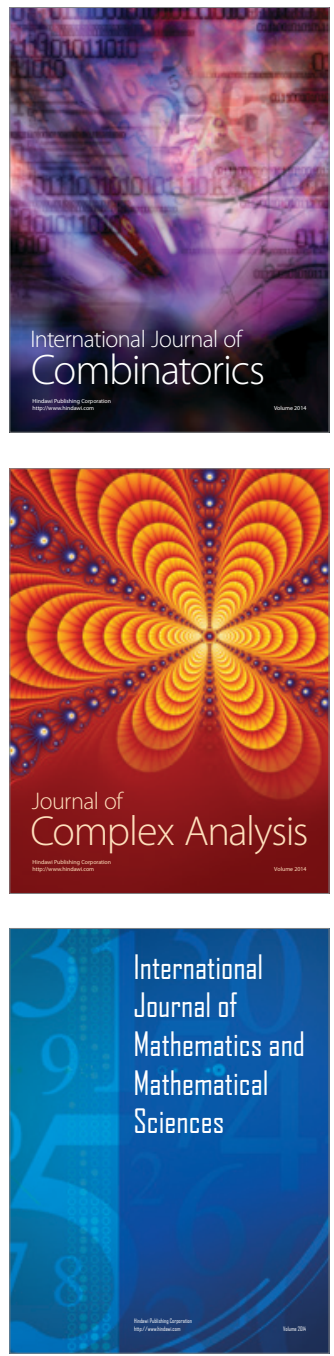
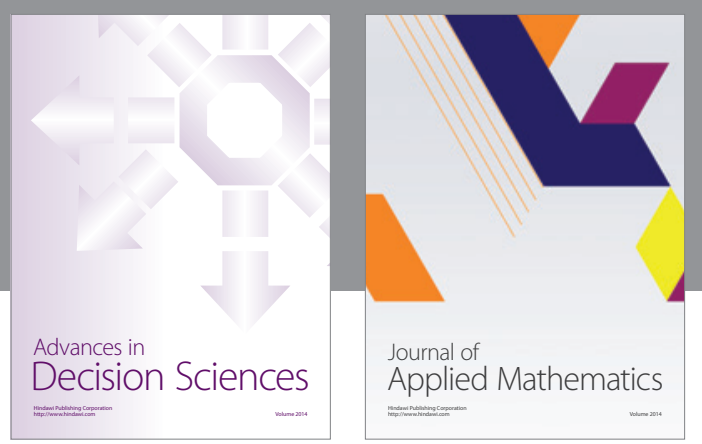

Algebra

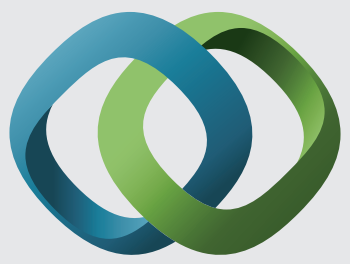

\section{Hindawi}

Submit your manuscripts at

http://www.hindawi.com
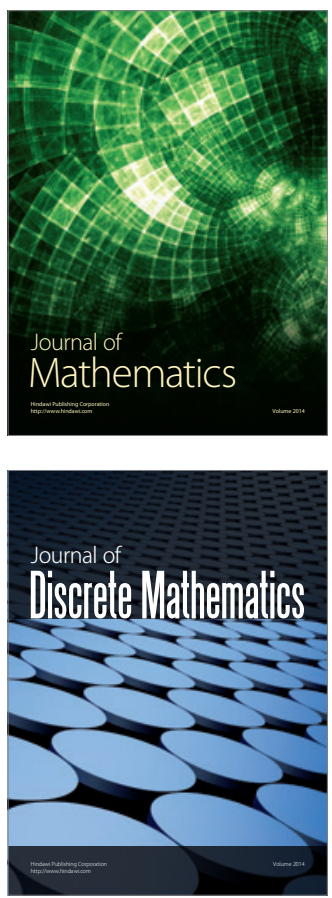

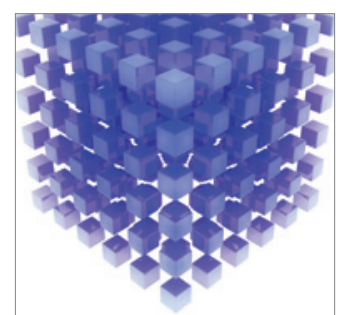

Mathematical Problems in Engineering
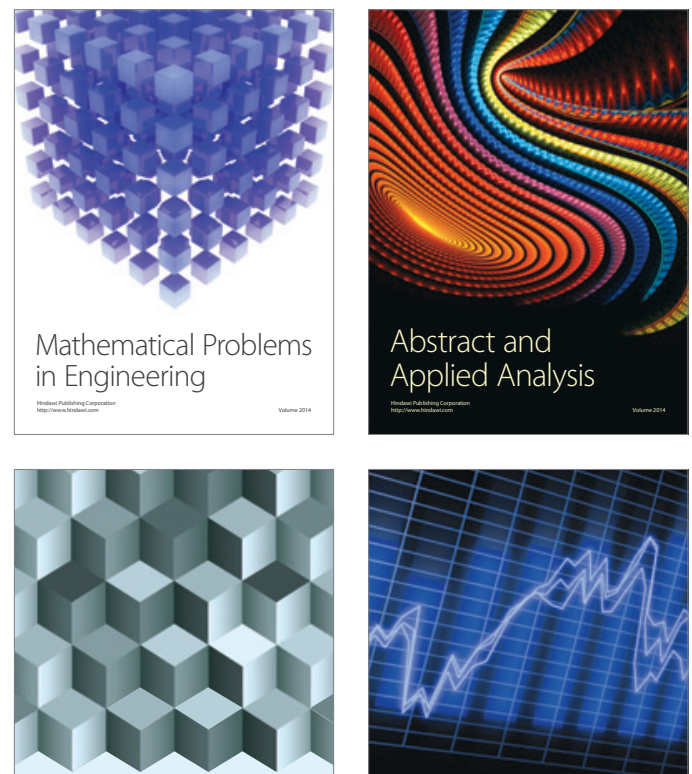

Journal of

Function Spaces

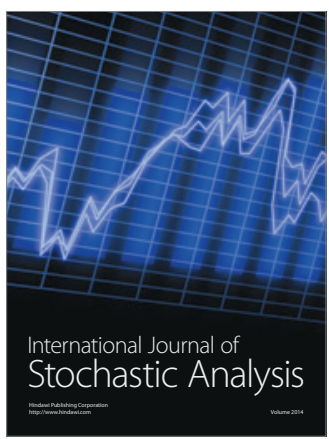

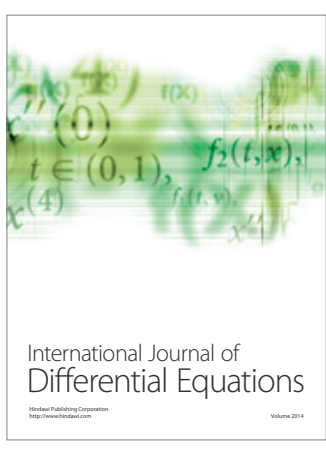
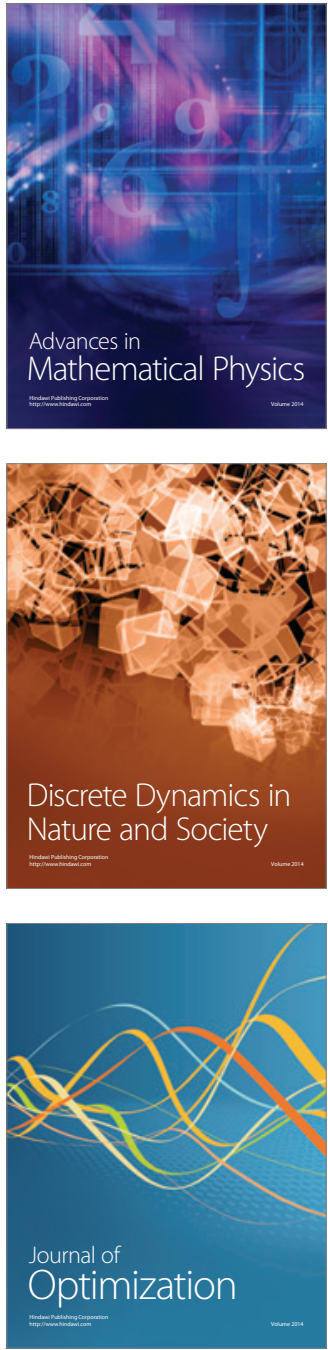